\title{
FAKE NEWS COMO DESAFIO PARA A CULTURA
}

\author{
Ivan Alexander Hegenberg \\ Mestre em Teoria Literária e Literatura Comparada pela Universidade de São Paulo (USP) \\ ivanhegenberg@gmail.com
}

\section{RESUMO}

Propõe-se uma reflexão sobre possíveis respostas de escritores, críticos e pesquisadores de literatura à disseminação em larga escala das notícias falsas, fenômeno que vem desestabilizando a democracia e levando a sociedade para posições de extremadireita, de forma especialmente sensível no Brasil e nos Estados Unidos, mas com potencial de avanço em praticamente todo o planeta. Um ponto de partida é o livro de Michiko Kakutani, A morte da verdade, que examina bastidores da indústria de fake news com dados relevantes e uma análise instigante a respeito do atual ambiente cultural. Abrese caminho para ponderações sobre aspectos de nosso ambiente cultural que possam ter tornado multidões inteiras suscetíveis a rejeitar os últimos vestígios do que nos parecia ser até pouco tempo atrás a noção de uma realidade compartilhada.

Palavras-chave: Literatura; política; pósmodernismo; Michiko Kakutani.

\begin{abstract}
This text proposes an approach on possible responses from literature writers, researchers and critics to the large-scale spreading of fake news, phenomenon that has been destabilizing democracy and leading society towards radical right-wing positions, especially in Brazil and United States, but with potential growth practically in the entire planet. A starting point may be Michiko Kakutani's book The death of truth, which examines the fake news industry behind the scenes, bringing relevant data and an insightful analysis about the contemporary cultural environment. A way is paved for evaluations of some aspects from our cultural environment that might have changed whole crowd susceptible to reject the last traces of what seemed to be the notion of a shared reality.
\end{abstract}

Keywords: $\quad$ Literature; politcs; postmodernism; Michiko Kakutani. 
Síntese para solucionar o problema da verdade? Verdade não é única, é compartilhada, coletiva, mas não é $100 \%$ relativa, pois está na práxis.

Paulo Freire

Não se trata de fenômeno isolado ou circunstancial. Foram constatadas enxurradas virtuais de notícias falsas em torno das eleições nos EUA a favor de Donald Trump, assim como no plebiscito do Brexit e na eleição presidencial brasileira, que culminou com a vitória de Jair Bolsonaro. Não é recomendável ignorar que a produção e a distribuição de fake news em escala industrial ameaçam as instituições democráticas e provocam uma perigosa onda de anti-intelectualismo. Aturdidos, no olho do furacão, perguntamo-nos que mecanismos de controle podem obter alguma eficácia diante de disseminação viral de "memes", vídeos e textos de caráter obscurantista. Parecem limitados os esforços dos administradores de serviços das redes sociais, pois mesmo quando porta-vozes do Facebook, do WhatsApp e plataformas semelhantes anunciam medidas para a contenção de fake news, os resultados obtidos são decepcionantes. Nem mesmo o combate a perfis falsos (incluídos aí milhares de robôs) tem alcançado o êxito desejado. Também se mostram pouco eficientes os desmentidos públicos e o confronto no campo das ideias, nestes tempos de compartilhamento instantâneo e "curtidas" compulsivas, quando até os boatos mais infundados prosperam nas redes sociais e penetram na consciência suscetível de milhões de pessoas.

Não há como negar que nos setores progressistas também prosperam mentiras e uso de perfis falsos, o que demanda reprovação e alerta, no entanto é notório que a indústria de fake news ocorre majoritariamente pela extrema direita. A razão para isso estará, em parte, no financiamento clandestino para tais atividades, oriundo da ala mais 
predatória do atual modelo econômico - empresários que visam a lucrar com a violência, com o desregulamento de leis ambientais e com o afrouxamento do combate ao trabalho escravo - contudo há de se levar em consideração também a maior facilidade de propagação de conteúdo de ódio, com uma manipulação engenhosa a inspirar medo contra os "diferentes". Não seria difícil constatar que tanto Trump quanto Bolsonaro apostaram em discursos de exclusão: o primeiro, tendo como principal promessa a construção de um muro na divisa com o México; e o segundo, ainda mais radical, foi capaz de render homenagem ao Coronel Brilhante Ustra, responsável por bárbaras torturas no DOI-CODI durante a ditadura. Os aspectos mais primitivos do ser humano são estimulados, às vezes de maneira explícita, outras vezes de forma mais velada, mas sempre de modo a criar inimigos imaginários tão detestados e temidos que o diálogo se encontra, na prática, impossibilitado.

Enquanto houver espaço para defesa da democracia, haverá trabalho de sobra para pesquisadores de ciências políticas e teóricos da comunicação, no entanto, cabe também uma linha de pesquisa conduzida por especialistas em literatura. Há, em nossa área, um incomensurável acúmulo de reflexões sobre a dinâmica entre invenção e realidade, a relação entre ética e estética e os mais variados jogos entre fatos e ficção que não são desprezíveis para a compreensão de uma sociedade que vem perdendo suas referências consensuais. Está debilitada a noção de mundo compartilhado, ou seja, cada vez menos se observa uma aceitação ampla de postulados capazes de balizar consensos mínimos para a compreensão da realidade e a organização da sociedade. A disputa de narrativas atingiu tal ponto de acirramento que parece não haver um único dado aceito de maneira pacífica, ao passo que as mais quiméricas fantasias cobiçam status de ciência sem sequer se valer de verificações adequadas. Cada um enxerga uma realidade à parte 
de acordo com seus filtros ideológicos, porém nos últimos anos temos visto tamanho acirramento que o discurso da objetividade se percebe desprestigiado em meio à multidão. Nesse contexto, pode ser valioso refletir sobre a ficção como uma aproximação oblíqua para com a realidade, perguntando-nos sobre as diferenças entre a invenção literária e as notícias deliberadamente enganosas, além de considerar que novas responsabilidades podem assumir escritores, professores, críticos e pesquisadores de literatura diante do desafio das fantasias mais destrutivas, disseminadas como se fossem notícias válidas.

Antonio Candido nos encoraja a reconhecer o papel da literatura no contexto social e estabelecer conexões com nossa realidade:

Nos países da América Latina a Literatura sempre foi algo profundamente comprometido com a construção e a aquisição de uma consciência nacional, de modo que o ponto de vista histórico-sociológico é indispensável para estudá-la. Entre nós, tudo se banhou de literatura, desde o formalismo jurídico até o sentido humanitário e a expressão familiar dos sentimentos. Por isso é difícil delimitar esse universo insinuante e multiforme (CANDIDO, 2006, p. 217).

Não havendo para nós uma delimitação precisa entre literatura e textos de viés mais "objetivo", pode ser proveitoso estudar o problema em amplitude, observando, contudo, que correlações de força se projetam. Quando falamos em fake news, não estamos lidando exatamente com um fenômeno novo, mas a intensidade e a gravidade das consequências, além do ritmo acelerado da propagação de boatos, tendem a nos deixar despreparados para apreender a situação atual. Ao levar o debate para uma discussão literária, veremos que o arcabouço intelectual ainda requer muitos esforços e que o repertório capaz de nos acudir ainda é restrito. Não obstante, em 2018, foi lançado 
um livro que merece atenção como tentativa de percorrer esses caminhos espinhosos. Trata-se de A morte da verdade, de Michiko Kakutani, que durante décadas foi uma das principais críticas culturais do The New York Times.

Em grande parte, o livro de Kakutani se empenha em apuração e levantamento de dados, e não é à toa que sua dedicatória se dirige "para os jornalistas de todo o mundo que trabalham para noticiar os fatos". Constata-se sua solidariedade para com colegas de redação de um dos maiores jornais do planeta, instituição que Trump tenta ferrenhamente desgastar ao acionar sua máquina de fake news. E são relevantes muitas das informações que Kakutani destaca, como, por exemplo, o uso de até 60 mil anúncios diferentes por dia no Facebook durante a campanha de Donald Trump. Contudo, o livro não deixa de ser o trabalho de uma crítica literária, contando com análises baseadas em um repertório afinado com suas especificidades. Um dos pontos que mais nos chamam à atenção é a aproximação que Kakutani estabelece entre as técnicas de persuasão empregadas por campanhas extremistas e as ferramentas conceituais pós-modernas. Trump, Bolsonaro e tantos outros nomes da direita radical travam uma ferrenha guerra cultural contra os parcos avanços progressistas das últimas décadas e, surpreendentemente, apropriam-se de muito do que foi teorizado e defendido por filósofos, artistas e escritores considerados anti-autoritários.

Provavelmente nem Trump nem Bolsonaro leram Derrida, Foucault e Baudrillard, ou estudaram arte conceitual ou participaram de alguma palestra sobre o fim das fronteiras entre literatura e realidade. No entanto, essas lideranças políticas são influenciadas por ideólogos com maior habilidade para beber de tais fontes, como é o caso de alguns estrategistas citados por Kakutani (Mike Cernovich e VladilavSurov, por exemplo). Como ressalta Kakutani, o fato de Trump ignorar as referências mais restritas a 
nichos acadêmicos e vanguardistas não significa uma impossibilidade de absorver conteúdo semelhante através de diluições mais acessíveis.

Os pós-modernistas dificilmente poderiam ser culpados por todo esse niilismo que paira livremente pelo planeta. Mas alguns corolários simplificados de seu pensamento se infiltraram na cultura popular e foram sequestrados pelos defensores do presidente (KAKUTANI; 2018, p. 54-55).

Quanto maior a diluição, maior a simplificação e a deturpação, o que nos obriga a ser cautelosos. Não deixa de ser pertinente, no entanto, observar que alguma comparação entre os discursos se sustenta. Seja em arautos do pós-modernismo, seja nas campanhas dos políticos de extrema-direita, há uma desconfiança aguda em relação a instituições estabelecidas que chega a inspirar até mesmo o desprezo por métodos científicos de verificação, culminando naquilo que Kakutani chama de "uma postura blasé com relação à verdade" (2018, p. 15). Os pensadores pós-modernos encararam a linguagem como um terreno tão instável que o sentimento de perda de contato com qualquer realidade aferível se torna incontornável. Foucault não poderia ser mais claro quando diz que "a profunda interdependência da linguagem e do mundo se acha desfeita. (...) as coisas e as palavras vão separar-se" (2007, p. 59). A linguagem fecha-se em si mesma e a auto-referência passa a ser a grande aposta de muitos artistas e escritores. 0 perigo decorrente é que com o esvaziamento da noção de realidade compartilhada, as "versões alternativas", os revisionismos e interpretações altamente subjetivas se propagam sem anteparos sólidos. A ideia de que não houve ditadura militar no Brasil, por exemplo, ganha força em um ambiente cultural que estimula o relativismo. Os fatos 
históricos passam a ser aceitos ou rejeitados de acordo com a convicção individual, sem maior necessidade de verificação.

Por outro lado, é necessário admitir que, muito antes de as ideias de Foucault e de outros pensadores de seu tempo serem diluídas e assimiladas com maliciosas deturpações, o estatuto da verdade já sofria fortes atentados. No final do século XIX, Nietzsche já operava uma ousada substituição do sistema de valores vigentes por uma genealogia das ideias, na qual é a vontade de poder que antecede a construção social de tudo o que será considerado racional. A psicanálise, a partir de Freud, apresenta o inconsciente como terreno movediço, onde o desejo é imperativo e deforma a percepção do mundo sob influência de pulsões inacessíveis ao intelecto. A Escola de Frankfurt, por sua vez, destaca que uma leitura exigente de Marx deve evitar dogmatismo e colocar o estatuto da verdade em xeque, uma vez que decifrar a ideologia é colocar o campo das ideias em disputa. Sendo assim, estaremos perdidos se, para marcar um contraponto às fake news, insistirmos na busca nostálgica por uma verdade que já não tem a solidez que outrora aparentava ter.

A principal lacuna no estudo de Kakutani está na falta de problematização de tais questões, o que a leva a empregar a palavra "verdade" como se fosse uma meta alcançável. É evidente, contudo, que não podemos ser irresponsáveis a ponto de aceitar a relativização total ou embarcar no niilismo. A verdade, mesmo que não seja alcançada em definitivo, precisa ser almejada e, ainda que se deva abrir espaço para o confronto de versões, é crucial exigir critérios mínimos para a validação de uma narrativa. $O$ fato de a ciência ser passível de revisões não pode jamais significar uma equivalência de opiniões, do contrário as investigações mais sérias perdem força diante das mais nocivas manipulações. É preciso redobrar a atenção para os bastidores e apostar sempre na 
versão mais confiável, no entanto, de acordo com as bases epistemológicas melhor fundamentadas de que dispomos no momento, é preciso admitir que existe uma crise da razão e uma impossibilidade de se fixar verdades incontestes.

A complexidade de nosso desafio aumenta quando reconhecemos que o relativo êxito dos pós-modernos em influir na cultura de massas é elemento a se considerar nesse ambiente propício à ascensão de extremistas, mas apenas em parte tal conjuntura decorre da ação do trabalho filosófico de desgaste do valor da verdade. Não compreendemos a situação de maneira adequada sem observar o ângulo oposto, ou seja, que figuras antidemocráticas ganham força como reação a um contexto onde todos os valores podem ser questionados. O fascismo europeu dos anos 1930 se utilizou de alguns elementos estilísticos e retóricos do Manifesto Comunista e da filosofia para espíritos livres de Nietzsche, mas não deixou de se aproveitar do abalo emocional que as novas ideias provocavam em grande parte da população. Hitler, Mussolini e Franco alimentaram o incipiente medo de perda de privilégios nas classes médias e altas, disparado mais pela percepção de novos espaços de fala para oprimidos do que por "ameaças comunistas" concretas em seus países; e contaram com a insegurança trazida por uma "ciência judaica" que levantava muitas questões sobre a sexualidade antes recalcada, além dos crescentes ataques contra a religião, que livros como o de Nietzche incentivavam. 0 Ministro da Propaganda nazista Joseph Goebbels não desperdiçou a chance de gerar uma campanha incessante de notícias falsas, e sabemos da eficácia que obtiveram na transformação dos judeus em bodes expiatórios destinados a canalizar aquilo que o alemão médio tinha de mal resolvido em sua psique e em sua consciência de classe. ${ }^{i}$

Assim como ocorreu no fascismo dos anos 1930, o fenômeno atual marca oposição a paradigmas mais intelectualizados, mas não deixa de, ao mesmo tempo, se 
aproveitar (indevidamente) de ferramentas conceituais de adversários, com adaptações grosseiras. É como se a eliminação do inimigo, para ser totalizante como exige a psicologia de todo fanático, abarcasse também uma antropofagia mal intencionada, diferente da proposta de Oswald de Andrade ${ }^{i i}$, por ser um devoramento negligente que, para não se deixar transformar pelo conteúdo deglutido, aproveita mal os ingredientes incorporados, digeridos com pouca reflexão.

Um aspecto que hoje é mais fácil de observar que nos anos 1930 é que a incerteza em relação aos critérios para a verdade acentua o narcisismo, restando como referência última apenas o eu impenetrável de cada um. Observa-se que o ego se coloca acima da ciência consolidada, a percepção da realidade se ajusta ao que o indivíduo se sente mais confortável em acreditar. A maioria não percebe, contudo, que se trata de um ego sequestrado, pois em nossa sociedade o indivíduo é exposto a estímulos contínuos para o consumo, para o sensacionalismo, para desejos imediatos e para a obediência mecânica aos interesses do patronato. A indústria cultural tem sido eficiente na redução de cidadãos a meros produtores e consumidores. Cabe atentar para o que escreveram Adorno e Horkheimer:

a diversão é o prolongamento do trabalho sob o capitalismo tardio. Ela é procurada por quem quer escapar ao processo de trabalho mecanizado, para se pôr de novo em condições de enfrentá-lo. Mas, ao mesmo tempo, a mecanização atingiu um tal poderio sobre a pessoa em seu lazer e sobre a sua felicidade, ela determina tão profundamente a fabricação das mercadorias destinadas à diversão, que esta pessoa não pode mais perceber outra coisa senão as cópias que reproduzem o próprio processo de trabalho (...). Para continuar a ser um prazer, não deve mais exigir esforço e, por isso, tem de se mover rigorosamente nos trilhos gastos das associações habituais (ADORNO; KORKHEIMER, 1985, p. 128). 
É evidente que são os setores mais ricos que têm maiores condições de insistir no bombardeio de sinais, pela TV, pela internet e na arena pública. Discursos que atinjam diretamente os impulsos mais primitivos terão chances consideráveis de sucesso e, dentro do pacote, podem se inserir as noções mais simplistas de hierarquia, no intuito de atribuir um enganoso senso de ordem diante do caos. A impossibilidade de uma realidade consensual faz com que muita gente terceirize a apreensão do mundo para figuras autoritárias, com as quais tenham alguma identificação narcísica, baseada em uma projeção, embora esse ego se alimente da ilusão de que seus interesses individuais coincidem com os interesses do líder.

Por mais que haja um movimento de retroalimentação, onde cada pequeno avanço de progressistas estimula uma reação conservadora, não se pode deixar de fazer a disputa. É importante atentar para a perseguição a artistas, no Brasil, desde antes mesmo da campanha eleitoral de 2018. Episódios como a polêmica insuflada artificialmente sobre a exposição Queermuseum, a tentativa de criminalizar artistas como Wagner Schwartz, a caracterização preconceituosa de todo artista como "vagabundo", as críticas rasas a iniciativas de fomento à cultura; todos esses ataques orquestrados por grupos agressivos da direita vão consolidando uma dura oposição entre o conservadorismo e um circuito de cultura mais libertário. Não é exagero dizer que há uma tentativa de extremistas de reduzir, no imaginário popular, a figura do artista para algo como um delinquente que se aproveita indevidamente de verbas públicas (nesse contexto, as palavras "mamata" e "pedófilo" se disseminaram muito pela internet nos últimos tempos). No Brasil, a síntese desse caldo está na propaganda anti-intelectualista travestida de filosofia de Olavo de Carvalho, protagonista das cruzadas contra o assim chamado "marxismo cultural". Descontado seu constante uso de palavrões, é um rigoroso 
domínio cristão junto à submissão incondicional ao capitalismo que se propõe quanto aos costumes e, para alcançar tal fim, um governo autoritário lhe parece desejável.

Essa frente de batalha tem grande valor estratégico, pois, ainda que existam alguns artistas que apoiam os caminhos conservadores que o país vem tomando, constata-se que na cena cultural a hegemonia está com as vozes progressistas. Grandes formadores de opinião com o prestígio e o alcance de Chico Buarque, Elza Soares, Mano Brown, Fernanda Montenegro, Nuno Ramos, Kleber Mendonça Filho, Raduan Nassar e milhares de vozes que repercutem com a ajuda da internet, se opõem ao desmonte do estado e ao aumento da opressão que assolam o país. Há uma intensa disputa de visões de mundo, de modos de vida. A abertura para a imaginação, para a alteridade, para a possibilidade de sonhos e desejos diversos, o exercício de questionamento, de comparação, de convívio com contradições, em suma, a educação emocional complexa que as grandes obras de arte ensejam pode ser uma vacina contra os discursos mais simplistas e apelativos que os extremistas propagam, muitas vezes recorrendo a fake news. O fortalecimento do plano simbólico se faz vital para resistir contra posições de fanatismo, não necessariamente com conteúdo panfletário explícito - embora algum grau de didatismo possa adquirir também validade estratégica.

Não há como negar que hoje ocorre, na América Latina, nos EUA e na Europa, um desgaste da política tradicional, uma crise da representatividade que abalou a confiança nos grandes partidos e até mesmo na democracia. As fake news potencializam um descontentamento que se nutre de uma desilusão anterior, afinal nem tudo pode ser facilmente catalogado como mentira. Teremos apenas um diálogo de surdos se, para nos contrapor a fake news, insistirmos na recuperação de programas que perderam grande parte de sua inocência, afinal as versões de que dispomos não se sustentam sem manchas 
e sem ressalvas. Por outro lado, o grande perigo é que o niilismo alimente a antipolítica, pois o desespero generalizado tende a acarretar saídas extremistas. É essencial reconhecer limites, imperfeições e equívocos, evitar o idealismo que não poderá ser cumprido, contudo afirmar propostas, fazer notar a diferença entre uma direção que amplia possibilidades e uma que restringe, entre um caminho que almeja um grau maior de emancipação humana e um que oprime. A melhor resposta para a rede de mentiras não é a verdade, mas a proposição de subjetividades mais complexas do que a do limitado homem resignado a bater continência. Talvez seja mais importante do que nunca enriquecer o espaço da fantasia como um contraponto à desumanização que divide a sociedade e trata a população como meros números.

Seja em setores mais intelectualizados ou mais populares, o enfrentamento de mentiras com a venda de ilusões ingênuas será insuficiente, pois até mesmo a ficção deve abarcar desencanto. Para qualquer estrato social que nos dirijamos, há uma dosagem a se administrar, para que não se caia no perigo da negação total - o niilismo que estimula a antipolítica. Nesse contexto, talvez seja preferível evitar produções que exaltem demais o ego, porém com o cuidado de permitir que a individualidade seja respeitada. As chances de êxito serão bem maiores se ficar claro que arte não se reduz à mercadoria, transmitindo valores para além da transação comercial, não se deixando subordinar plenamente ao sistema vigente. É preciso acreditar que até mesmo as pessoas mais alienadas guardam um sonho de superação de uma realidade que as oprime, e que, portanto, a identificação com o opressor é potencialmente reversível.

Há muito a ser dito que não será possível esmiuçar em um artigo curto como este, porém se faz aqui o convite para futuras reflexões e a intensificação do diálogo nesse terreno espinhoso. Por ora, o essencial é que artistas, professores e pesquisadores de 
literatura se reconheçam como vetores de transformação e se disponham a pensar em como construir um ambiente cultural, onde as notícias falsas encontrem maiores obstáculos do que têm encontrado atualmente. É contraproducente partir do pressuposto que intelectuais e artistas pouco interferem no mundo real, pois mesmo diante de uma derrota se pode acumular forças e alimentar expectativas futuras, ainda que em um trabalho de formiga. Não há uma direção só, nem um único procedimento, no entanto evidencia-se uma responsabilidade coletiva. Com isso, talvez seja recomendável que toda negatividade esteja em dialética para não se paralisar e que o relativismo e o niilismo sejam evitados nestes momentos em que a hesitação pode custar caro. Enquanto muitas mentes conscientes e criativas ainda menosprezam seu próprio potencial, os poderosos que visam silenciá-las o fazem justamente porque as temem e vislumbram a força que essa oposição pode obter.

\section{Referências}

ADORNO, T; HORKHEIMER, M. Dialética do esclarecimento. Rio de Janeiro: Jorge Zahar Editor, 1985.

ANDRADE, Oswald. Manifesto antropófago. Disponível em: <http://www.ufrgs.br/cdrom/oandrade/oandrade.pdf>. Acesso em: 28 maio 2019.

CANDIDO, Antonio. A educação pela noite. Rio de Janeiro: Ouro sobre Azul, 2006. FOUCAULT, Michel. As palavras e as coisas. São Paulo: Martins Fontes, 2007. FREUD, Sigmund. Freud 1930-1936 - O mal-estar na civilização e outros textos. São Paulo: Companhia das Letras, 2010.

FREIRE, Paulo. Pedagogia do oprimido. São Paulo: Paz e Terra, 1997. 
JAMESON, Fredric. Pos-modernismo: a lógica cultural do capitalismo tardio. São Paulo: Ática, 2007.

KAKUTANI, Michiko. A morte da verdade: Notas sobre a mentira na era Trump. Rio de Janeiro: Intrínseca, 2018.

MARX, Karl. Manifesto comunista. São Paulo: Boitempo, 2010.

NIETZSCHE, Friedrich. Genealogia da moral. São Paulo: Companhia das Letras, 2003.

Recebido em 17 de maio de 2019. Aceite em 09 de novembro de 2019.

\footnotetext{
'Em 1930, no ensaio "O mal-estar na civilização", Freud havia alertado para possibilidades trágicas de manipulação em larga escala ao estudar a psicologia das massas.

ii O Manifesto Antropófago que Oswald de Andrade publicou no Correio da Manhã, em 1924, traz sínteses totalizantes, como na máxima "só a antropofagia nos une", porém enseja uma comunhão libertária, nãodogmática: "contra todas as catequeses". Disponível em: <http://www.ufrgs.br/cdrom/oandrade/oandrade.pdf>. Acesso em: 28 maio 2019.
} 